- This paper illustrates the importance that patients place on clinical attire.

- Patients prefer formally dressed clinicians who look clean and professional.

- Patients are supportive of the use of in-surgery protective equipment such as facemasks and safety glasses.

- The patients in this study preferred dental staff to wear name badges.

- Dental staff should consider patients' opinions on clinical attire and make modifications if required.

\title{
Patient preferences for dental clinical attire: a cross-sectional survey in a dental hospital
}

\author{
G. McKenna, ${ }^{1}$ G. R. R. Lillywhite ${ }^{2}$ and N. Maini ${ }^{3}$
}

\begin{abstract}
Aims and objectives This cross sectional descriptive study was designed to survey patient opinion towards dental clinical attire, name badges and commonly used cross-infection control measures.

Method Patients attending a dental hospital for a consultation appointment were asked to complete a questionnaire accompanied by photographs of models portraying a range of clinical attire. A representative sample of patients completed 188 questionnaires over a four week period.

Results The study found that the majority of patients felt clinical attire was important and that they preferred dental professionals to wear name badges. The majority of patients also preferred dentists to use both safety glasses and face masks. When asked to indicate which clinical attire was most appropriate for a consultant/specialist to wear, the overwhelming opinion was that of smart dress accompanied with a white coat. In addition, most respondents wished their dentist to wear a traditional white, dental tunic.

Concluding remarks It is hoped that this study will be informative for the dental team and that the results will be taken into consideration when considering appropriate clinical attire in accordance with patient opinions.
\end{abstract}

\section{INTRODUCTION}

Professionalism is an image that promotes a successful relationship with the patient and thus enables the foundation of effective patient care. ${ }^{1}$ This fundamental connection is created during the first meeting where the patient forms a initial impression

\footnotetext{
${ }^{1 *}$ General Professional Trainee, ${ }^{2}$ Specialist in Prosthodontics, Honorary Specialist Registrar/Clinical Lecturer in Restorative Dentistry, ${ }^{3}$ General Professional Trainee, Edinburgh Postgraduate Dental Institute, Floor 4 Lauriston Building, Lauriston Place, Edinburgh, EH3 9HA

*Correspondence to: Mr Gerald McKenna

Email:g.mckenna@ucc.ie
}

\section{Refereed Paper}

Accepted 24 April 2007

DOI: $10.1038 /$ bdj.2007.1109

${ }^{\circ}$ British Dental Journal 2007; 203: 681-685 of the clinician. ${ }^{2}$ Walsh suggested that proper appearance formed part of the essential elements for development of this successful professional relationship. ${ }^{3}$

A considerable amount of research dealing with the professional image of healthcare providers has been produced, but very little of this has been specific to the practice of dentistry. In reviewing the literature produced on patient attitudes to medical staff attire, we see a strong preference for a traditionally dressed physician in contrast to a more casual appearance. Typically, the white coat forms part of the formally dressed physician's wardrobe. Its origins date from the introduction of aseptic surgery by Lister in the late 19th century when surgeons began wearing all-white garments to protect the patient and surgeon from contamination. Many articles illustrate that patients prefer medical personnel to wear a white coat as part of their professional attire. ${ }^{4-6}$ Psychologists have often stated the importance of physical appearance and its effect upon first impressions and interpersonal relationships. ${ }^{7}$ It is this initial impression which can influence patients' expectations of care and help to create an opinion as to the professional's level of competence. ${ }^{7-9}$

Whilst we are aware of the image that professionals may wish to convey through their physical appearance, there are a number of other factors that also influence attire. Cross-infection control is a vitally important issue in all aspects of medical practice and plays an increasingly influential role in some of the outfits and protective accessories worn. It is only natural that people wish to feel comfortable whilst working and often choose attire to accommodate this. In addition, constraints are often placed on how professionals dress by uniforms prescribed by those who employ them. We would hope, however, that many of these important factors have been considered in the design of suitable uniforms.

In this study we focused on the importance of patients' opinions towards their dental professional based on their physical appearance. We wanted to know how important clinical attire is to dental patients and if our image of a traditionally dressed professional was still the most appropriate. In the modern world 
of clinical dental practice we are already seeing signs that the dentist-patient relationship is moving towards a customerbased service, with increasing demands and pressures. Patient opinions can change very quickly and it is essential that the profession keeps informed in order to provide the service that our patients expect.

\section{METHODS}

A cross-sectional descriptive study using survey methodology was conducted of new patients attending an outpatient dental facility for consultation appointments. A self-completion questionnaire was developed to gather data on patients' opinions on dental clinical attire, name badges and a number of cross-infection control procedures.

A pilot study was conducted by asking 20 patients and members of staff to complete the questionnaire. The participants were asked for their opinions on the usability and clarity of the questionnaire. The feedback was positive but indicated that use of the phase 'dental consultant' was causing some confusion. As a result, this was replaced with 'dental consultant/specialist' to improve understanding. After this revision the questionnaire was then widely distributed.

The questionnaires were distributed to consecutive new patients prior to an initial consultation appointment and after completion of a written medical history form. The questionnaire was accompanied by a consent form and information sheet explaining the purpose of the research and providing a promise of confidentiality. The information sheet also assured patients that they were free to abstain from participation if they chose. Patients were excluded from the study if they were unable to speak English, illiterate or for any other reason which would impede their understanding of the questionnaire. The questionnaires were completed in the waiting area prior to the participants' appointments and were dispensed by a nonclinical member of staff. A total of 192 questionnaires were distributed over an eight week period beginning February 1 2006. A copy of the questionnaire is included as Figure 1.

The demographic information collected from the questionnaire included the respondent's age and sex. Respondents were asked to rate how important they felt dental clinical attire was by using a modified Likert scale ( 1 = very important, 2 = important, 3 = quite important, 4 = unimportant).

We then asked for patient opinions on two commonly used in-surgery cross-infection control measures: face masks and safety glasses. Respondents were given the choice of three possible responses to indicate whether they preferred their dentist to use these measures, were indifferent to their use or preferred for them not to be worn.

Patients were asked to observe a number of photographs numbered 1-6 depicting a male and female model wearing a variety of clinical attires (Fig. 2).

In each of the photographs the same background was used and the following characteristics remained constant: hairstyle, facial expression, presence of jewellery and physical appearance (except for attire). The style of dress was the only variant across each of the photographs.

Respondents were asked to indicate which numbered clinical attire they felt best portrayed what a dental consultant/specialist and then a dentist should wear.

Using a checklist system, patients were asked to look at the

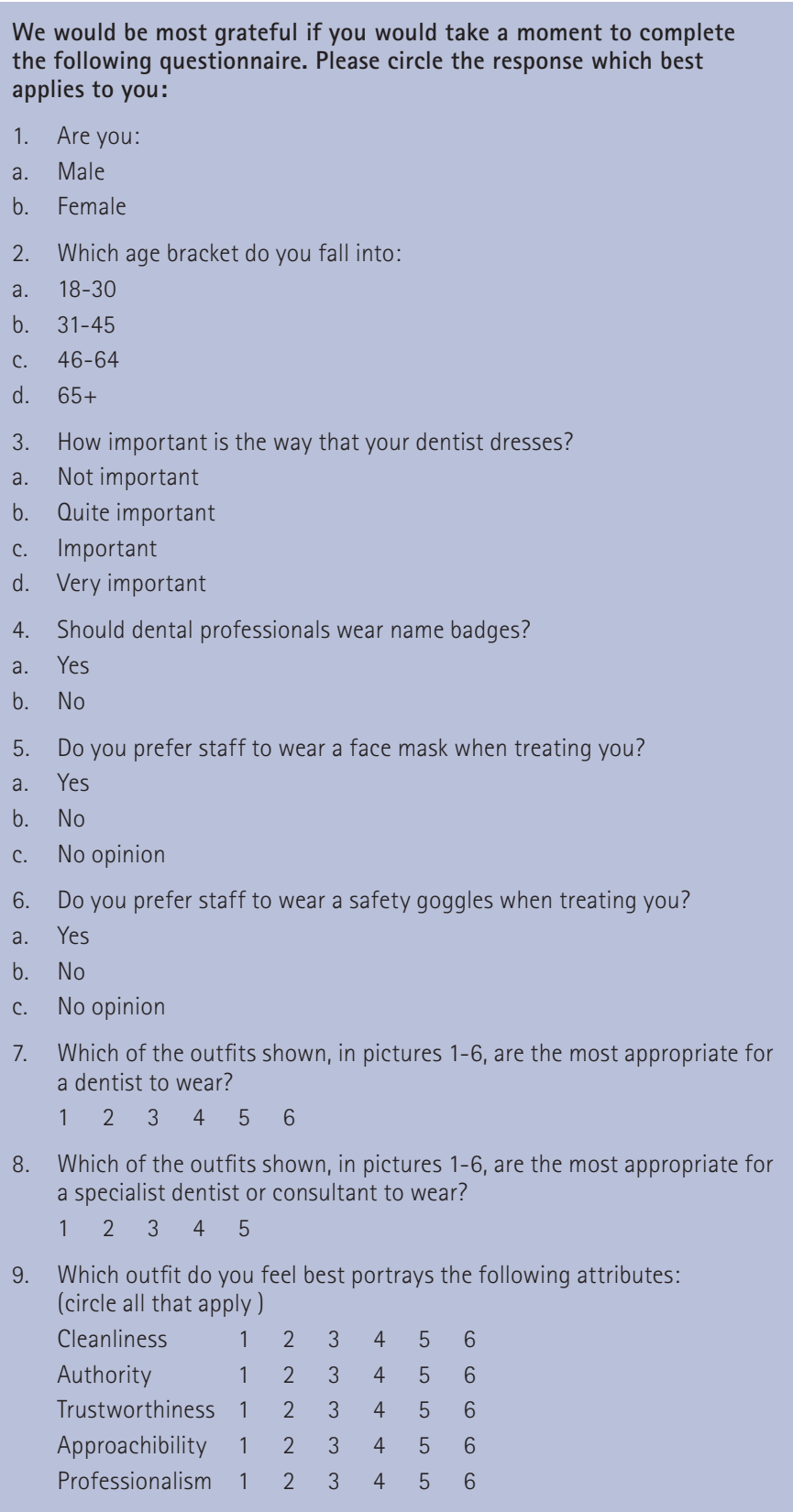

Fig. 1 The study questionnaire

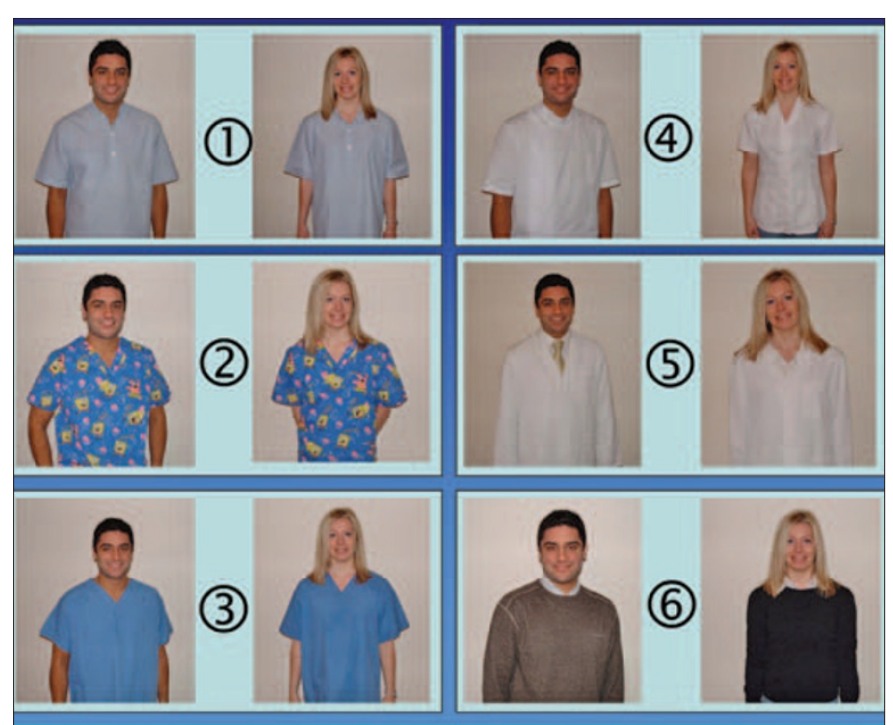

Fig. 2 Options for clinical attire as shown to participants 
numbered clinical attires and to indicate which they felt best portrayed the qualities of cleanliness, professionalism, authority, trustworthiness and approachability.

Completed patient questionnaires were collected and passed blind to an independent statistician where they were analysed for response frequency and the results tabulated. Descriptive statistics and chi-squared analysis for non-parametric data with the appropriate degrees of freedom were performed on the data to assess responses to the questionnaire items across patient age groups and gender. Statistical significance was determined at $\mathrm{p}<0.05$.

\section{RESULTS}

Over the eight weeks, 192 questionnaires were distributed. One hundred and eighty-eight successfully completed questionnaires were returned. Four questionnaires were spoiled, two were not completed due to time constraints and two more did not complete all sections. The response rate was therefore 98\%. A total of six patients declined to complete the questionnaire (1.6\%).

The surveyed patient pool consisted of 115 females (61\%) and 73 males (39\%). Of the respondents, the majority came from the 46-64 years age bracket (48\%) followed by the 65 years and over (26\%). The mean age of the sample was 47.4 years (range 18-86 years).

Of those sampled, 117 patients (62\%) rated the significance of how a dentist dresses as very important or important. Only nine patients (5\%) indicated they felt it was unimportant. Further analyses of these results indicated that female respondents rated the significance of clinical attire as more important than males (Table 1). A chi-squared test indicated a strong statistically significant difference between males and females ( $p \leq 0.001$ ).

Those patients from older age groups also placed more emphasis on the importance of their dentist's attire (Table 2). When responses from the 18-30 years group were compared with those patients of 46 years and older, a statistically significant difference was observed ( $\mathrm{p} \leq 0.01$ ).

The vast majority of patients sampled (93\%) indicated that they preferred members of staff to wear name badges. This was an opinion held by all groups regardless of gender and age.

The questions on cross-infection control procedures revealed that patients preferred dentists to wear safety goggles (56\% of respondents) (Table 3). Statistical testing produced no significant difference between responses from males and females. A chi-squared test showed strong statistical evidence ( $p \leq 0.001)$ of a difference between younger (18-30 years) and older participants $(46+$ years).

The majority of patients also favoured the use of face masks, with $72 \%$ of respondents indicating that they preferred these to be worn (Table 4). A higher percentage of younger participants indicated that they preferred the use of face masks but there was no significant difference observed between the patient groups.

When respondents were asked to indicate which of the clinical attires they felt was most appropriate for a dental consultant/specialist to wear, $147(78 \%)$ of them chose option 5 (formal attire with a white coat).

When asked to indicate what they felt a dentist should wear, 107 patients (57\%) chose a traditional white tunic, 41 patients $(22 \%)$ chose surgical scrubs and 18 patients (10\%) chose a modern tunic (Table 5).

\begin{tabular}{|c|c|c|c|c|c|}
\hline \multirow[b]{2}{*}{ Gender } & \multicolumn{4}{|c|}{ How important is a dental professional's attire? } & \multirow[b]{2}{*}{ p-value } \\
\hline & $\begin{array}{l}\text { Very } \\
\text { important } \\
(\%)\end{array}$ & $\begin{array}{l}\text { Important } \\
(\%)\end{array}$ & $\begin{array}{l}\text { Quite } \\
\text { important } \\
(\%)\end{array}$ & $\begin{array}{l}\text { Unimportant } \\
(\%)\end{array}$ & \\
\hline $\begin{array}{l}\text { All } \\
\text { patients }\end{array}$ & 30.3 & 31.9 & 33.0 & 4.8 & \multirow{3}{*}{0.001} \\
\hline Male & 19.0 & 33.7 & 37.3 & 10.8 & \\
\hline Female & 36.0 & 36.8 & 27.2 & 0 & \\
\hline
\end{tabular}

Table 2
respondents' age
\begin{tabular}{|l|l|l|l|l|}
\hline \multirow{2}{*}{ Age } & How important is a dental professional's attire? \\
\cline { 2 - 5 } & $\begin{array}{l}\text { Very } \\
\text { Important (\%) }\end{array}$ & Important (\%) & $\begin{array}{l}\text { Quite } \\
\text { Important (\%) }\end{array}$ & $\begin{array}{l}\text { Unimportant } \\
(\%)\end{array}$ \\
\hline $18-30$ & 22.6 & 29.0 & 35.5 & 12.9 \\
\hline $31-45$ & 25.6 & 32.6 & 32.6 & 9.3 \\
\hline $46-64$ & 32.1 & 28.3 & 37.7 & 1.9 \\
\hline $65+$ & 36.1 & 36.1 & 27.9 & 0 \\
\end{tabular}

\begin{tabular}{|c|c|c|c|}
\hline \multirow{2}{*}{ Age } & \multicolumn{3}{|c|}{ Do you prefer your dentist to wear safety glasses? } \\
\hline & Yes (\%) & No $(\%)$ & Do not care (\%) \\
\hline $18-30$ & 63 & 18 & 19 \\
\hline $31-45$ & 65 & 14 & 21 \\
\hline $46-64$ & 41 & 37 & 22 \\
\hline $65+$ & 43 & 40 & 17 \\
\hline
\end{tabular}

Table 4 Opinions on use of face masks according to respondents' age

\begin{tabular}{|l|l|l|l|}
\hline \multirow{2}{*}{ Age } & \multicolumn{3}{|l}{ Do you prefer your dentist to wear face masks? } \\
\cline { 2 - 4 } & Yes (\%) & No (\%) & Do not care (\%) \\
\hline $\mathbf{1 8 - 3 0}$ & 75 & 8 & 17 \\
\hline $31-45$ & 78 & 9 & 13 \\
\hline $46-64$ & 68 & 18 & 14 \\
\hline $65+$ & 64 & 17 & 19 \\
\hline
\end{tabular}

Younger participants showed a stronger preference for less traditional clinical attires such as surgical scrubs and the modern tunic when compared to older age groups (Table 6). Statistical testing illustrated a significant difference ( $p \leq 0.01)$ between the choices of patients from the 18-30 years group and those over 65 years.

One hundred and seventeen patients (62\%) indicated that they felt that a white coat best portrayed cleanliness, whilst 53 patients $(27 \%)$ chose a traditional white tunic. One hundred and seven respondents (57\%) felt a white coat best portrayed professionalism and 152 patients (81\%) indicated it also 


\begin{tabular}{|c|c|c|}
\hline Clinical Attire & $\begin{array}{l}\text { Number of } \\
\text { respondents }\end{array}$ & $\begin{array}{l}\begin{array}{l}\text { Percentage of } \\
\text { respondents }\end{array} \\
\end{array}$ \\
\hline 1. Modern dental tunic & 18 & 10 \\
\hline 2. Paediatric surgical scrubs & 8 & 4 \\
\hline 3. Plain surgical scrubs & 41 & 22 \\
\hline 4. Traditional dental tunic & 107 & 57 \\
\hline 5. Smart dress with white coat & 14 & 7 \\
\hline 6. Casual dress & 0 & 0 \\
\hline
\end{tabular}

\begin{tabular}{|c|c|c|c|c|c|c|c|}
\hline \multirow{2}{*}{ Age } & \multicolumn{6}{|c|}{ Clinical attire } & \multirow{2}{*}{$p$-value } \\
\hline & 1 & 2 & 3 & 4 & 5 & 6 & \\
\hline $18-30$ & 5 & 1 & 10 & 14 & 1 & 0 & \multirow{2}{*}{0.01} \\
\hline $65+$ & 8 & 0 & 2 & 42 & 10 & 0 & \\
\hline
\end{tabular}

communicated authority. When asked to express which outfit conveyed trustworthiness, 79 patients (42\%) chose the traditional dental tunic with 73 patients (39\%) picking the white coat. The majority of patients (85 respondents) felt that the dental tunic best illustrated approachability, with 72 patients (38\%) choosing the surgical scrubs.

\section{DISCUSSION}

The purpose of this study was to measure patient opinions on dental attire and cross-infection control measures commonly used in the dental surgery. We measured opinions using a cross-sectional survey of new patients attending a dental hospital for consultation appointments.

Over an eight week period we achieved a sample size of 188 patients. The questionnaires returned a high response rate of $98 \%$. The sample size produced a representative sample of new patients attending a dental hospital. The demographics indicated that the majority of patients were female with a mean age of 47.4 years. A larger sample size may have produced results with a decreased statistical margin of error but this was not achievable in a realistic timeframe.

The setting for the study was a tertiary healthcare facility receiving patients on a referral-only basis, therefore all those surveyed had previous experience of dentistry. In an attempt to reduce bias, the questionnaires were distributed by nonclinical reception staff prior to patients entering the clinical environment. We were very aware of the lasting consequences of first impressions and those created by the clinical staff could have influenced our results.

\section{Name badge use}

The results indicated that the majority of patients prefer dental professionals to wear a name badge. This is in keeping with previous studies found in medical literature. ${ }^{10,11}$ In addition, this result is not surprising in a hospital setting where patients are new to the environment. It would be anticipated that results would be different in a dental practice where patients already know which dentists they are seeing and may not feel a name badge is necessary. ${ }^{12}$

In an audit conducted in the same dental hospital as part of the study, it was found that only 15\% of staff were observed to be wearing visible name badges in the clinical environment. However, name badges are considered a cross-infection risk. A more appropriate solution could be the incorporation of an integral or embroidered tag as part of staff uniform.

\section{Cross-infection control measures}

The dental profession uses a varying degree of protective equipment as part of cross-infection control. Whilst recommendations exist on the use of protective equipment and crossinfection measures, ${ }^{13}$ variety exists between different surgeries and clinicians. ${ }^{14}$ However, safety glasses and facemasks are considered standard in the modern surgery.

The majority of respondents (56\%) preferred their dentist to wear safety glasses. Younger patients were significantly more receptive to safety glasses compared with older respondents ( $p \leq 0.001$ ). However, a large proportion of participants had no strong feelings on the matter (28\%). The general public may not be aware of potential transmucosal transmission of infective diseases and so may not perceive a discernable benefit from their dental professional wearing this safety product.

Mask use was preferred by the majority of patients (72\%) and these results were supported by the findings of Shulman's study in $2001 .{ }^{15}$ There was no discernable difference between male and female respondents, but younger patients appeared to be more agreeable to mask use than older patients. This difference of opinion could be attributed to the fact that younger patients have always experienced dentistry with protective masks in use, whilst older generations have witnessed the changes that have occurred with in-surgery protective measures. In retrospect, it may have been interesting to investigate if patients were aware of the importance of wearing protective measures in the clinical setting.

\section{Clinical attire}

The results indicate that patients have strong opinions on how dental professionals dress. A large majority of patients $(62 \%)$ felt this was either important or very important. Female respondents placed much more emphasis on the importance of dental attire than males ( $p \leq 0.001)$.

The results indicate that patients have a strong preference for dental consultants or specialists wearing formal clinical attire including a white coat (78\%). A majority of patients felt that this attire portrayed the qualities of cleanliness, professionalism and authority. A review of the literature did not reveal studies on dental attire so direct comparison of these findings was not possible. However, it is widely reported that patients prefer medical personnel to be smartly dressed, despite debate amongst medical colleagues about the wearing of white coats. ${ }^{12,16,17}$ In addition, patients seemingly prefer the appearance of physicians who wear neckties, ${ }^{18}$ although this item of clothing coupled with a white coat has obvious cross-infection implications. ${ }^{19-21}$ This preference appears to translate to senior dental professionals also.

Somewhat surprisingly the results gathered suggest that patients prefer their dentist to wear a traditional white tunic 
(57\%). Recently there has been a move away from the traditional tunic towards a more modern design, perhaps motivated by improving comfort. The respondents felt that the traditional tunic portrayed cleanliness, trustworthiness and approachability. These opinions may come from their experience of dentistry in the practice setting, where many professionals wear tunics.

\section{CONCLUSIONS}

This study has implications for all branches of dentistry where dental professionals strive to deliver a patient-centred service. We have drawn attention to the importance of physical appearance and its effect upon first impressions and interpersonal relationships. From this study we can conclude that patients place a great deal of emphasis on how dental professionals dress. They are supportive of the appropriate use of protective equipment such as facemasks and safety glasses and prefer their dentist to wear them. They also prefer dental professionals to wear name badges. Those sampled in this study expressed a strong preference for smartly dressed dental consultants and specialists who wear a white coat. In addition, patients prefer their dentist to wear a traditional white dental tunic. Having this insight into patient preferences should enable individuals and organisations to set standards for appropriate dress codes for dental professionals.

Future research could focus on patient opinions towards dress codes for other members of the dental team including dental care professionals. It may also be useful to determine patient opinions on dress codes in the general practice and community dental services. In addition, it may be informative to survey patient attitudes towards dental students' attire. Students operate in an environment where the development of a successful working relationship is paramount given the relative inexperience of the clinician. This is also the setting where our younger colleagues begin to understand the values of professionalism which will positively influence their future practising careers.

1. Brosky M, Keefer 0 , Hodges J, Pesun I, Cook G. Patient perceptions of professionalism in dentistry. J Dent Educ 2003; 67: 909-915.

2. Short D. First impressions. Br J Hosp Med 1993; 50: 270-271.

3. Walsh K C. Projecting your professional image. Imprint 1993; 40(5): 46-49.

4. Rehman S U, Nietert P J, Cope D W, Kilpatrick A O. What to wear today? Effect of doctor's attire on the trust and confidence of patients. Am J Med 2005; 118: 1279-1286.

5. Brase G L, Richmond J. The white-coat effect: physician attire and perceived authority, friendliness and attractiveness. J App/ Soc Psycho/ 2004; 34: 2469-2481.

6. Kanzler M H, Gorsulowsky D C. Patient's attitudes regarding physical characteristics of medical care providers in dermatological practices. Arch Dermatol 2002; 138: 463-466.

7. Bershield E, Gangestad S. The social psychological implications of facial attractiveness. Clin Plast Surg 1982; 9: 289-296.

8. Mangum S, Garrison C, Lind C, Hilton H G. First impressions of the nurse and nursing care. J Nurs Care Qual 1997; 11(5): 39-47.

9. Cha A, Hecht B R, Nelson K, Hopkins M P. Resident physician attire: does it make a difference to our patients? Am J Obstet Gynecol 2004; 190: 1484-1488.

10. Taylor P G. Does the way housestaff physicians dress influence the way patients initially perceive their competence? Paediatric Notes 1985; 9: 1.

11. Gjerdingen D K, Simpson D E, Titus S L. Patients' and physicians' attitudes regarding the physician's professional appearance. Arch Intern Med 1987; 147: 1209-1212.

12. Matsui $D, C h o M$, Rieder M J. Physicians' attire as perceived by young children and their parents: the myth of the white coat syndrome. Pediatr Emerg Care 1998; 14: 198-201.

13. British Dental Association. Advice sheet A12: infection control in dentistry. London: British Dental Association, 2003.

14. Fabiani L, Mosca G, Giuliani A R. Hygiene in dental practices. Eur J Paediatr Dent 2006; 7: 93-97.

15. Shulman E R, Brehm W T. Dental clinical attire and infection-control procedures. $J$ Am Dent Assoc 2001; 132: 508-516.

16. Zwart D L, Kimpen J L. The white in paediatrics: link between medical history and preference for informally dressed physicians. Ned Tijdschr Geneeskd 1997; 141: 2020-2024.

17. Gonzalez Del Ray J A, Paul R I. Preferences of parents for paediatric emergency physicians' attire. Pediatr Emerg Care 1995; 11: 361-364.

18. Pronchik D J, Sexton J D, Melanson S W, Patterson J W, Heller M B. Does wearing a necktie influence patient perceptions of emergency department care? J Emerg Med 1998; 16: 541-543

19. Wong D, Nye K, Hollis P. Microbial flora on doctors' white coats. BMJ 1991; 303: 1602-1604.

20. Littlechild $\mathrm{P}$, Macmillan A, White M M, Steedman D. Contamination of skin and clothing of accident and emergency personnel. BMJ 1992; 305: 156-157.

21. Loh W, Ng V V, Holton J. Bacterial flora on the white coats of medical students. J Hosp Infect 2000; 45: 65-68. 